\title{
Modelling of Airport Rigid Pavement for Complex Configuration of Landing Gears and for a Large Spectrum of Cement Concrete
}

\author{
Radu Cojocaru ${ }^{1, \text { a }}$, Radu Andrei ${ }^{2, b}$, Mihai Budescu ${ }^{3, c}$ \\ 1,2,3 "Gheorghe Asachi" Technical University of lasi, \\ Faculty of Civil Engineering and Building Service, \\ Dimitrie Mangeron Blvd. no. 43, postal code 700050, lasi, Romania, \\ aradu_cojocaru82@yahoo.com; 'radu.andrei.d@gmail.com; 'mbsinfex@yahoo.com
}

Keywords: airport rigid pavement, six wheel bogie, finite element method, design diagrams

\begin{abstract}
The purpose of this paper is to develop new design diagrams in order to complete the actual Romanian standard. This addendum is justified by the fact that the current design diagrams are elaborated for a single value of the $\mathrm{E}$ - dynamic elasticity modulus (in Romanian standard $\mathrm{E}=$ $30000 \mathrm{MPa}$ ) and of the Poisson ratio (in Romanian standard $v=0.15$ ). Therefore the diagrams from the Romanian standard NP034-99 do not permit the design for other types of concrete cement with improved characteristics with elasticity modulus $\mathrm{E} \geq 30000$ until $\mathrm{E}=50000 \mathrm{MPa}$ or of the Rolled Compacted Concrete (RCC) with Poisson ratio $v=0.25$ or of the other concrete types as cement concretes with recycled aggregates or steel fibre reinforced concrete.

The first part of the paper presents the stress design methodology based on the finite element software and on the parameters which interfere in the design calculation. In addition to the diagrams from the Romanian standard which apply only to an external load up to a four wheel bogie, the diagrams with loads with six wheel bogie are introduced.

Further are shown the differences between the stress calculated with single values from the actual Romanian standard and the stress calculated with the exact values of the considered parameters [E - dynamic elasticity modulus and the Poisson ratio].

The study relies on the specific load of modern aircrafts (like Airbus - A380, Boeing - B777) that have six footprints tire in the landing gear structure.

In the end, the article brings forward a graphic comparison analysis between the diagrams of the Romanian current standard and the ones conducted in the present study by using FEM (Finite Element Method). Furthermore, a design case study exemplifies the method used to obtain the slab thickness for an airport rigid pavement structure using an external load from a complex landing gear with six footprints tire.
\end{abstract}

\section{Introduction}

The introduction of new construction materials for airport pavement structures like concrete with superior qualities with different modules of elasticity (reinforced concrete with dispersed steel fibres, RCC - Rolled Compacted Concrete, cement concrete with recycled materials), as well as the evolution of new aircrafts (like Airbus - A380, Boeing - B777) which have complex landing gear with six footprint tire, determine the need to improve the design methods in order to allow the use of new design parameters. The thickness of concrete slab for runway is obtained by using several diagrams which are made to cover different values of external loads and various geometries of landing gears. To determine a rigid pavement thickness from these diagrams, the subgrade modulus $(\mathrm{k})$, the allowable working stress and the weight on one main landing gear must be known.

Considering the diverse geometry of the landing gear with six footprints tire, the new diagrams can be based on an average landing gear with the most disadvantageous geometry. The new developed design diagrams complete the actual Romanian standard for design of airport rigid pavement NP034-99. 


\section{The Computation Model with Finite Element}

The Ansys 11 tridimensional finite element computer software had been used to determine the $\sigma_{t}$ tensile stress needed to complete the design diagrams. The computation model consists of the concrete slab uniformly resting on the foundation layer.

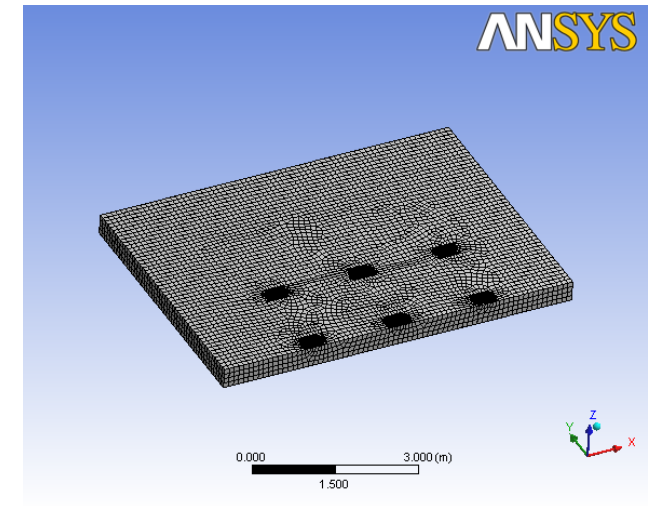

Fig. 1- Finite Element mesh of the slab in D2 loading position

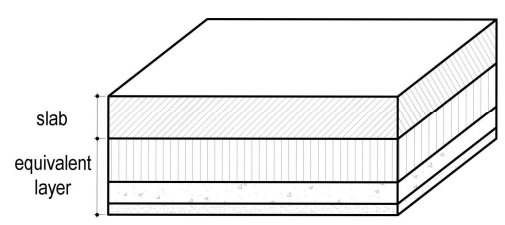

a)

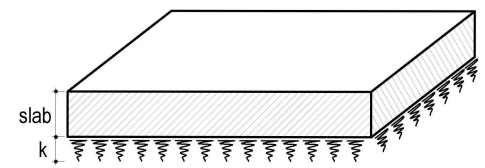

b)

Fig. 2. a) components of rigid pavement structure; b) computation model

The rigidity of the foundation layer is given by the reaction modulus (k) (fig. 2. b) which can be calculated using AASHO Road test/ SBA-STBA- type relation. According to the layers sub adjacent to the concrete slab, using table 6 the equivalent thickness $\left(\mathrm{H}_{\mathrm{eq}}\right)$ of the layers is calculated, by multiplying each layer by an equivalence coefficient. The reaction modulus at the surface of the foundation layer $(\mathrm{k})$ is determined using the chart in fig. 12, according to reaction modulus of the foundation layer $\left(\mathrm{k}_{0}\right)$ and the equivalent thickness of the layers. For each calculation model the concrete slab has meshed in a minimum of 4 layers of finite element, and in the area of transfer of loads from the landings gear a finer meshing of finite elements had been provided in order to obtain more precise values of $\sigma_{t}$ (fig. 1). For each finite element simulation a plane dimension of $5.00 \times 7.00 \mathrm{~m}$ has been adopted for the concrete slab, as the maximum technologically available dimension. This plane dimension of the concrete slab has been chosen because the distance between the contraction-bending transverse is big, providing the highest degree of comfort for the passengers and also because this dimension generates the highest levels of $\sigma_{t}$ stress.

The weight of the aircraft is transmitted to the concrete slab in the form of uniformly distributed loads in a quasi-elliptical area (fig. 3). As this quasi-elliptical area requires higher calculating times, a rectangular loading area can be adopted by using area equivalence formulas (length $L=0.8172 L_{e}$ and width $l=0.6 L$ where $L_{e}{ }^{2}=A / 0.5227$ - length of elliptical tire print) [5, 10]. The rectangular area leads to $\sigma_{t}$ covering values.

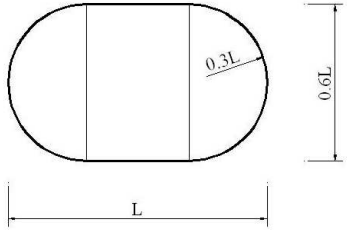

a)

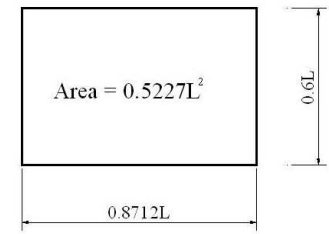

b)

Fig.3. a) quasi elliptical real area; b) rectangular equivalent area;

In order to obtain the highest/ the most disadvantageous $\sigma_{t}$ values, the plane-loading position of the concrete slab must be studied. Thus, several simulations had been performed, in different loading positions, as follows: D1-centre of slab, D2- tangential to the length of the slab, D3- at the corner of the slab and D4- tangential to the contraction-expansion joint. It was concluded that the D2 loading position generates the highest $\sigma_{t}$ tensile stress values. 
The current Romanian standard is using 4 types of landing gear, whose features are displayed in Tab. 1: single wheel, dual, twin tandem, tandem (fig. 4).

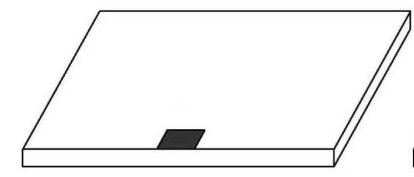

a) single wheel

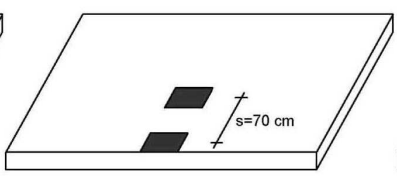

b) dual

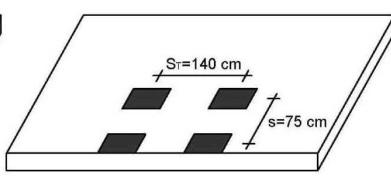

c) twin-tandem

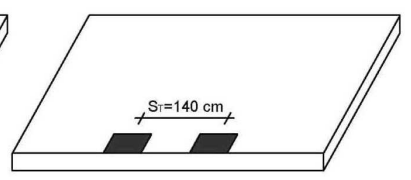

d) tandem

Fig. 4 - Tire prints of representative landing gears in D2 loading position

Table. 1. Characteristics of representative landing gear

\begin{tabular}{|c|c|c|c|c|}
\hline $\begin{array}{c}\text { Representative } \\
\text { landing gear }\end{array}$ & $\begin{array}{c}\text { Gauge }(\mathrm{s}) \\
{[\mathrm{cm}]}\end{array}$ & $\begin{array}{c}\text { Tire print }(\mathrm{ST}) \\
{[\mathrm{cm}]}\end{array}$ & $\begin{array}{c}\text { Tire pressure } \\
{[\mathrm{MPa}]}\end{array}$ & $\begin{array}{c}\text { Maximum } \\
\text { load }[\mathrm{t}]\end{array}$ \\
\hline Single wheel & - & - & 0,60 & $0.3 \ldots 0.6$ \\
\hline Dual & 70 & - & 0,90 & $0.6 \ldots 1.2$ \\
\hline Twin -Tandem & 75 & 140 & 1,20 & $1.0 \ldots 1.6$ \\
\hline Tandem & - & 140 & 0,60 & $0.4 \ldots 0.8$ \\
\hline
\end{tabular}

In order to supplement/ improve the existing diagrams, 6 wheel bogie had been added. Because the geometry of the 6 tire footprint landing gears is different between aircraft types and manufacturers, it was concluded that the landing gear of the Airbus 380 is the most representative of its class, generating the most disadvantageous tensile stress. The Airbus A380 has the biggest take-off weight as well as the most complex landing gear (fig. 5, tab. 2). The big distance between the landing gears justifies taking into account the influence of each landing gear, separately.

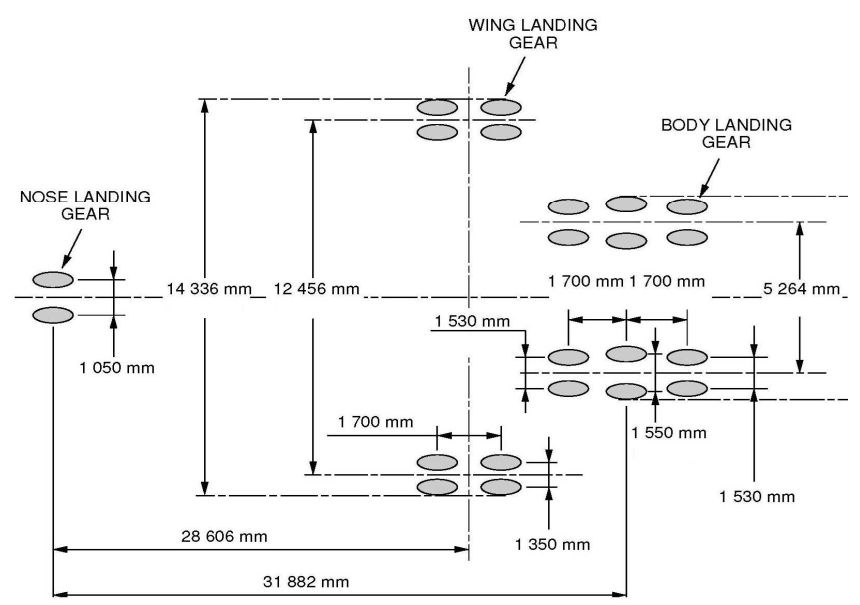

Table 2. Maximum pavement loads for A380800 different models

MRW - Maximum ramp weight

VNG - maximum vertical noise gear ground load VWG - maximum vertical wing gear ground load

Fig.5. Landing gear footprint for Airbus A380-800

\section{Influence of Dynamic Elasticity Modulus Value. (E-MPa)}

This study has been realized in order to highlight the necessity to elaborate diagrams for more values of the elasticity modulus. In the current Romanian standard the diagrams are elaborated for an $\mathrm{E}$ value of $30000 \mathrm{MPa}$, lacking the possibility of dimensioning of airport rigid pavement that are composed of the above mentioned materials. Table 3 presents the differences between the $\sigma_{t}$ values if the real values of the elasticity modules would have been used. The differences between the $\sigma_{t}$ values obtained can be observed for the booth values of Poisson ratio. The utilization of the designed diagrams from the current Romanian standard results in major errors in the design process in the case of materials with $\sigma_{t}$ values different of $30000 \mathrm{MPa}$.

The study has been made for a concrete slab with the dimension of $5.00 \times 7.00 \mathrm{~m}$ in plane and a thickness of $20 \mathrm{~cm}$. The loading position is the D2 position using two values of external load for one body landing gear $(\mathrm{P})$ : 145t, 160t. This loading was applied trough six footprint tire landing 
gear (Fig.5). There are four variants for the reaction modulus at the surface of the foundation layer: $\mathrm{k}_{1}=20 \mathrm{MN} / \mathrm{m}^{3}, \mathrm{k}_{2}=40 \mathrm{MN} / \mathrm{m}^{3}, \mathrm{k}_{3}=80 \mathrm{MN} / \mathrm{m}^{3}, \mathrm{k}_{4}=150 \mathrm{MN} / \mathrm{m}^{3}$.

In order to highlight the rise of the $\sigma_{t}$ tension, the simulation was made for four values of the dynamic elasticity modulus: $\mathrm{E}_{1}=25000 \mathrm{MPa}, \mathrm{E}_{2}=30000 \mathrm{MPa}, \mathrm{E}_{3}=40000 \mathrm{MPa}, \mathrm{E}_{4}=50000 \mathrm{Mpa}$.

The differences obtained, of up to $13 \%$ on the $\sigma_{t}$ tension values (tab.3), justify the design of rigid pavement airport structures for effective values of the dynamic elasticity modulus E.

Table. 3 -Percent difference of value $\sigma_{t}$ depending on different values of the E-dynamic elasticity modulus

\begin{tabular}{|c|c|c|c|c|c|c|c|c|c|c|c|}
\hline \multicolumn{12}{|c|}{$\mathrm{H} 20(\mathrm{~cm})$} \\
\hline \multicolumn{6}{|c|}{$\mathrm{P} 145(\mathrm{kN})$} & \multicolumn{6}{|c|}{$\overline{\mathrm{P} 160(\mathrm{kN})}$} \\
\hline $\mathrm{K}\left(\mathrm{MN} / \mathrm{m}^{3}\right)$ & $E(\mathrm{MPa})$ & $\mathrm{v} 0,15$ & $\%$ & $\mathrm{v} 0,25$ & $\%$ & $\mathrm{~K}\left(\mathrm{MN} / \mathrm{m}^{3}\right)$ & $\mathrm{E}(\mathrm{MPa})$ & $\mathrm{v} 0,15$ & $\%$ & $\mathrm{v} 0,25$ & \\
\hline \multirow{4}{*}{20} & 25000 & 9.7593 & & 10.0120 & & \multirow{4}{*}{20} & 25000 & 10.728 & & 11.07 & \\
\hline & 30000 & 10.037 & 2.77 & 10.3700 & 3.45 & & 30000 & 11.103 & 3.38 & 11.472 & 3.50 \\
\hline & 40000 & 10.645 & 8.32 & 10.9720 & 8.75 & & 40000 & 11.731 & 8.55 & 12.137 & 8.79 \\
\hline & 50000 & 11.071 & 11.85 & 11.4670 & 12.69 & & 50000 & 12.247 & 12.40 & 12.685 & 12.73 \\
\hline \multirow{4}{*}{40} & 25000 & 8.5417 & & 8.8022 & & \multirow{4}{*}{40} & 25000 & 9.4491 & & 9.7373 & \\
\hline & 30000 & 8.8268 & 3.23 & 9.0981 & 3.25 & & 30000 & 9.7645 & 3.23 & 10.065 & 3.26 \\
\hline & 40000 & 9.3031 & 8.18 & 9.5969 & 8.28 & & 40000 & 10.291 & 8.18 & 10.616 & 8.28 \\
\hline & 50000 & 9.6975 & 11.92 & 10.0120 & 12.08 & & 50000 & 10.728 & 11.92 & 11.075 & 12.08 \\
\hline \multirow{4}{*}{80} & 25000 & 7.5505 & & 7.7700 & & \multirow{4}{*}{80} & 25000 & 8.3525 & & 8.602 & \\
\hline & 30000 & 7.7992 & 3.19 & 8.0353 & 3.30 & & 30000 & 8.6277 & 3.19 & 8.8889 & 3.23 \\
\hline & 40000 & 8.2018 & 7.94 & 8.4589 & 8.14 & & 40000 & 9.0801 & 8.01 & 9.3575 & 8.07 \\
\hline & 50000 & 8.5417 & 11.60 & 8.8022 & 11.73 & & 50000 & 9.4491 & 11.61 & 9.7373 & 11.66 \\
\hline \multirow{4}{*}{150} & 25000 & 6.7424 & & 6.9399 & & \multirow{4}{*}{150} & 25000 & 7.4586 & & 7.6771 & \\
\hline & 30000 & 6.9696 & 3.26 & 7.1741 & 3.26 & & 30000 & 7.71 & 3.26 & 7.9363 & 3.27 \\
\hline & 40000 & 7.3398 & 8.14 & 7.5559 & 8.15 & & 40000 & 8.1195 & 8.14 & 8.3586 & 8.15 \\
\hline & 50000 & 7.6377 & 11.72 & 7.8670 & 11.78 & & 50000 & 8.449 & 11.72 & 8.7028 & 11.79 \\
\hline
\end{tabular}

\section{Poisson Ratio Influence (v)}

Table 4 presents the differences regarding the value of $\sigma_{t}$ for $v=0.25$, using the value $v=0.15$ as a benchmark for the same variation of calculation parameters. The differences of up to $4 \%$ between the $\sigma_{\mathrm{t}}$ values presented in table 4 justifies the elaboration of diagrams for a value of $v=0.25$ needed for the designed of the rigid road structure made of RCC and RCC reinforcement with steel fibers [8].

Table 4. The influence of Poisson ratio (v) on $\sigma_{t}$ tension

\begin{tabular}{|c|c|c|c|c|c|c|c|c|c|}
\hline \multicolumn{10}{|c|}{$\mathrm{H} 20(\mathrm{~cm})$} \\
\hline $\mathrm{K}\left(\mathrm{MN} / \mathrm{m}^{3}\right)$ & $\mathrm{E}(\mathrm{MPa})$ & $\mathrm{v} 0,15$ & $\mathrm{v} 0,25$ & $\%$ & $\mathrm{~K}\left(\mathrm{MN} / \mathrm{m}^{3}\right)$ & $\mathrm{E}(\mathrm{MPa})$ & $\mathrm{v} 0,15$ & $\mathrm{v} 0,25$ & $\%$ \\
\hline \multirow{4}{*}{20} & 25000 & 9.7593 & 10.0120 & 2.59 & \multirow{4}{*}{80} & 25000 & 7.5505 & 7.7700 & 2.91 \\
\hline & 30000 & 10.037 & 10.3700 & 3.32 & & 30000 & 7.7992 & 8.0353 & 3.03 \\
\hline & 40000 & 10.645 & 10.9720 & 3.07 & & 40000 & 8.2018 & 8.4589 & 3.13 \\
\hline & 50000 & 11.071 & 11.4670 & 3.58 & & 50000 & 8.5417 & 8.8022 & 3.05 \\
\hline \multirow{4}{*}{40} & 25000 & 8.5417 & 8.8022 & 3.05 & \multirow{4}{*}{150} & 25000 & 6.7424 & 6.9399 & 2.93 \\
\hline & 30000 & 8.8268 & 9.0981 & 3.07 & & 30000 & 6.9696 & 7.1741 & 2.93 \\
\hline & 40000 & 9.3031 & 9.5969 & 3.16 & & 40000 & 7.3398 & 7.5559 & 2.94 \\
\hline & 50000 & 9.6975 & 10.0120 & 3.24 & & 50000 & 7.6377 & 7.8670 & 3.00 \\
\hline
\end{tabular}

\section{Temperature Variations Stress}

The length of the concrete cement slab is changing because of seasonal variations (winter-summer, night-day variations). Therefore, the concrete slab is deforming as a result of different temperatures of the two sides (top and bottom). The concrete slab is deforming with the nods down when the top of the slab has higher temperatures then the bottom (Fig. 6) and with the nods up when the reverse phenomena happens (Fig. 7).

Tensile stress occurs in the first case and compression in the second due to the tendency of the slabs weight to oppose the deformation [8]. The stress from temperature variations is being calculating with the finite element software using temperature gradient equal to $0.67 \mathrm{xH}_{\text {slabin }}$ in $\mathrm{D} 2$ loading position. 


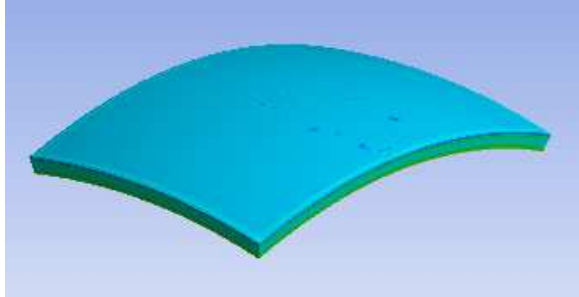

Fig.6

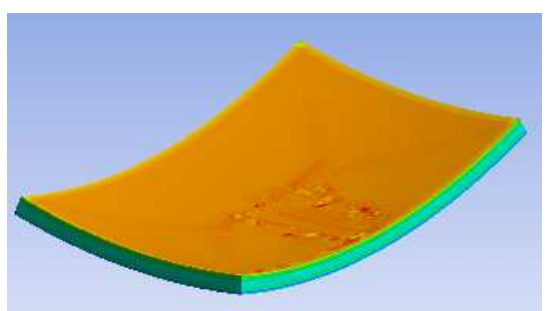

Fig.7

This type of calculation methodology substitutes the old Bradbury formulas. The stresses from temperature variations calculated with finite element method (FEM) have significantly lower values so their used is being justified because it's avoiding oversize.

The values of $\sigma \mathrm{t}$ in the design diagrams elaborated in this research represent the sum of values of stress $\Delta \sigma t \Delta \mathrm{t}$ derived from temperature variations and the $\sigma \mathrm{t}$ stress values resulted from external loads.

\section{Determination of Design Diagrams}

By using tri-dimensional finite element software Ansys 11, we obtain the values of $\sigma_{\mathrm{t}}$ of the below considered parameters which stand at the basis of the specific design diagrams newly developed.

The considered parameters are:

- Young modulus: $E_{1}=25000 \mathrm{MPa}, E_{2}=30000 \mathrm{MPa}, E_{3}=40000 \mathrm{MPa}, E_{4}=50000 \mathrm{MPa}$;

- Poisson's ratio: $v_{1}=0.15, v_{2}=0.25$

- Slab dimensions: $L$ x $l=7.00 \times 5.00 \mathrm{~m}$

- Reaction modulus $\mathrm{k}: \mathrm{k}_{1}=20 \mathrm{MN} / \mathrm{m}^{3}, \mathrm{k}_{2}=40 \mathrm{MN} / \mathrm{m}^{3}, \mathrm{k}_{3}=80 \mathrm{MN} / \mathrm{m}^{3}, \mathrm{k}_{4}=150 \mathrm{MN} / \mathrm{m}^{3}$

- The thickness of the concrete slab fluctuates between 20 and $40 \mathrm{~cm}$, with a rate of $5 \mathrm{~cm}$.

- The external load for one body landing gear (P): 145t, 160t, 170t, 175t

- The dimension of loading area $57 \times 34 \mathrm{~cm}$.

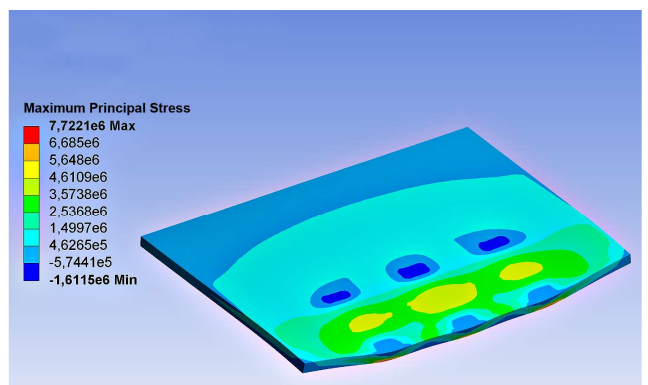

Fig. 8. $\sigma_{t}$-deformed of the slab using 6 wheel bogie load in $D 2$ position

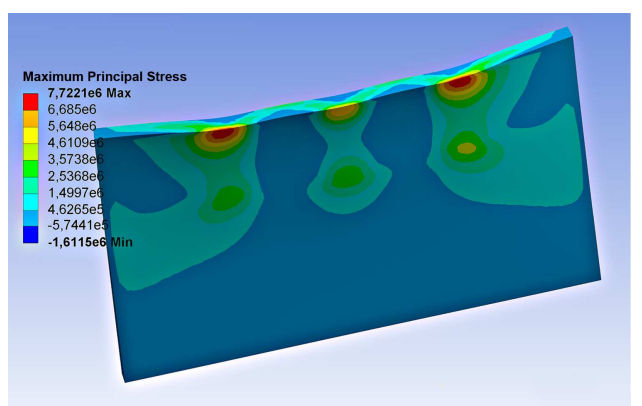

Fig. 9. $\sigma_{t}$-deformed of the slab using 6 wheel bogie load in D2 position (base of the slab)

To cover all the parameters field it has been used the results from the finite element method to create 32 diagrams: $\sigma_{t}=f(K, H) ; H=f\left(\sigma_{t}, K\right)$. Figure 10 presents only 2 of the diagrams for a single external load for one body landing gear $\mathrm{P}=145 t$ and for one value of Poisson ratio $v=0.15$. The design diagrams are used first, to determine the thickness of the slab- $H$, and secondly, to verify the value of bending tensile stress $\sigma_{t}$, if the other values are known. The Y-coordinate (ordinate) represents at normal scales the values of the concrete for bending tensile stress $\sigma_{t}[\mathrm{MPa}]$, while the $\mathrm{X}$-coordinate (abscissa) represents the thickness of the concrete slab $\mathrm{H}_{\text {slab }}$. 

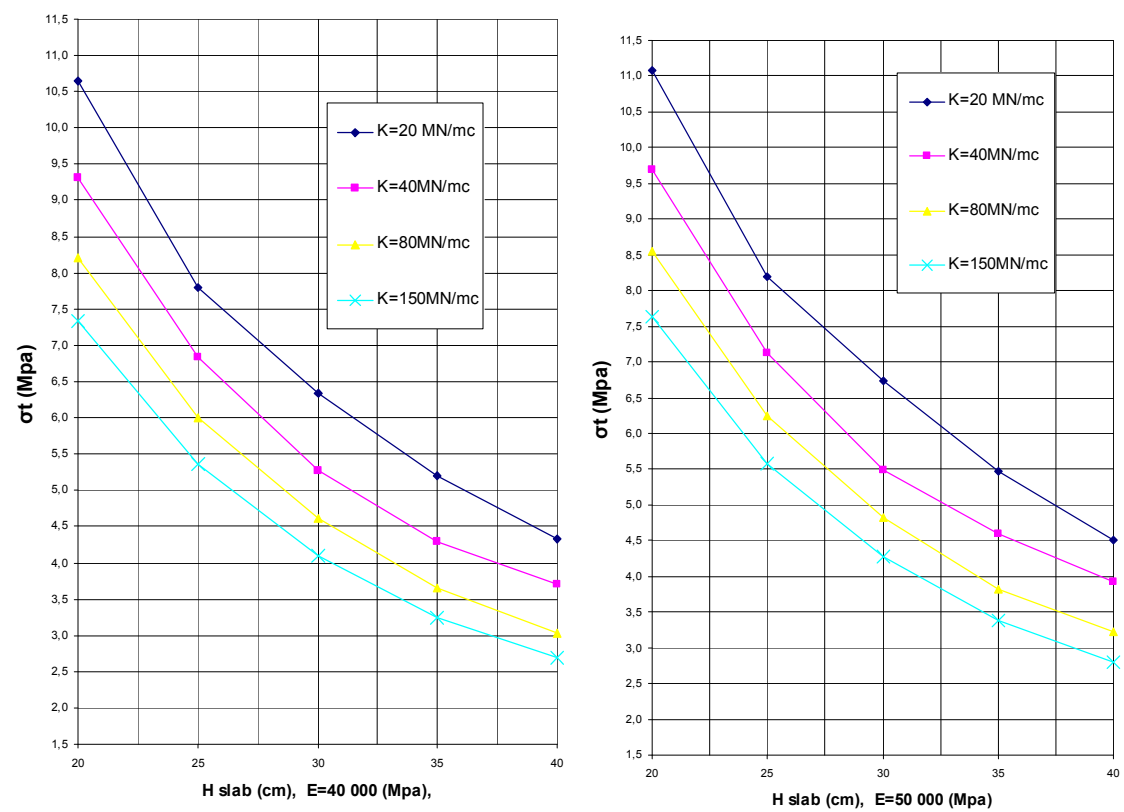

Fig. 10. Diagram - six footprint tire, $P=145 t, v_{1}=0.15$

\section{The Correlation Function of the Diagrams}

After the elaboration of the design diagrams we have performed the study of correlation functions for the precise determination of the in-between values of $\sigma_{t}$. In this study the CurveExpert computer software has been used. The Weibull (1) correlation function has been proven to be the most accurate in determining the correlation (Fig. 11). The coefficients of the correlation function for a single design diagram are presented in table 5. The Weibull correlation function can be used to avoid man made errors in the design diagrams interpretation phase.

$$
\sigma_{t}=a-b \cdot e^{\left(-c \cdot H^{d}\right)} .
$$

Table 5. The coefficients of Weibull interpolation

\begin{tabular}{|c|c|c|c|c|}
\hline $\mathbf{E}=\mathbf{4 0} 000[\mathrm{MPa}]$ & \multicolumn{4}{|c|}{ Weibull Model: $\boldsymbol{\sigma t}=\mathbf{a}-\mathbf{b}^{*} \exp \left(-\mathbf{c}^{*} \mathbf{H}^{\wedge} \mathbf{d}\right)$} \\
\hline $\mathrm{K}\left[\mathrm{MN} / \mathrm{m}^{3}\right]$ & $\mathrm{a}$ & $\mathrm{b}$ & $\mathrm{c}$ & $\mathrm{d}$ \\
\hline 20 & 12.43 & 8.97 & 1034595 & -3.69 \\
\hline 40 & 11.55 & 8.90 & 38344 & -3.41 \\
\hline 80 & 9.13 & 6.80 & 324911 & -4.01 \\
\hline 150 & 8.15 & 6.09 & 356447 & -4.03 \\
\hline
\end{tabular}

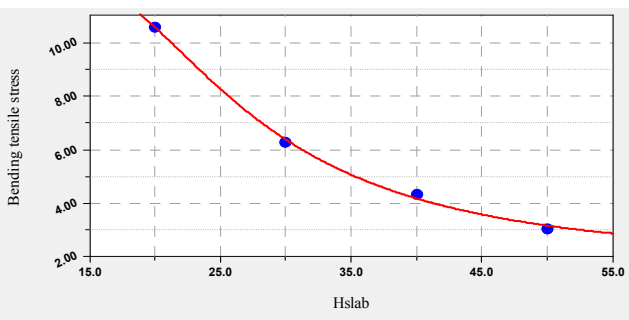

Fig. 11. The graphic for one of interpolation function for one diagram

Structural Design Criterion. Considering $\sigma_{\mathrm{t}}$ as the flexural tensile stress at the slab base and $\sigma_{\text {tadm }}$ as the allowable flexural tensile stress, the formula: $\sigma_{t} \leq \sigma_{\text {tadm }}$ represents the structural design criterion. The allowable flexural tensile is equal to the concrete tensile strength $\mathrm{R}_{\text {tigo, }}$, determined at the age of 90 days. The safety coefficient $c_{s}: \sigma_{\mathrm{tadm}}=\mathrm{R}_{\mathrm{ti90}} / \mathrm{c}_{\mathrm{s}}$ is applied to $\sigma_{\mathrm{tadm}}$.

The values of the safety factor: $c_{s}=1.8 \ldots 2.6$, depend on the type of the transfer device used at the joints, as well as the adverse geotechnical, climatic and traffic conditions [10].

Comparison analysis between the diagrams of the Romanian current standard and the ones conducted in the present study by using FEM. To achieve this comparison the following parameters have been chosen for the finite element design: the external loads from aircraft are transmitted through dual landing gear with $\mathrm{P}=17.5 \mathrm{KN}$; the values of reaction modulus at the surface layer $\mathrm{k}=$ $150 \mathrm{MN} / \mathrm{m}^{3}$; the values of Young modulus: $\mathrm{E}_{1}=25000 \mathrm{MPa}$ and Poisson Ratio $v_{1}=0.15$. The values from the current standard were determined from the design diagrams with the same parameters. In fig. 12 it can be noticed the minor differences between the values obtained by the two methods, they vary depending on the thickness of the slab considered. 


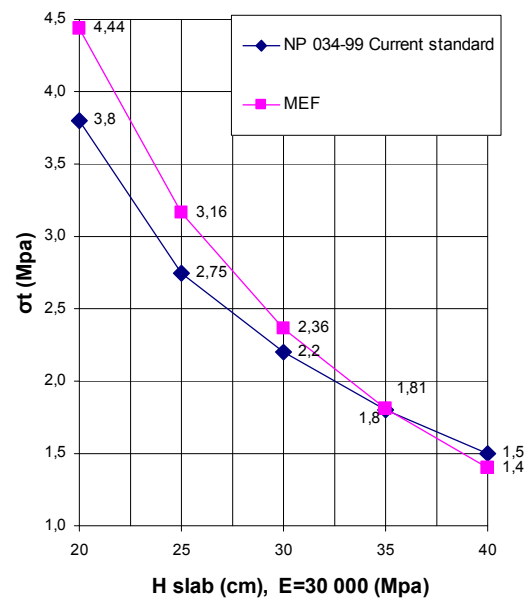

Fig. 12 Comparison analysis between current standard NP34-99 and MEF

Design example of a rigid airport pavement structure for loading of an Airbus A380 with complex landing gears with $512 \mathrm{tf}$ takeoff mass.

After the type of concrete used for the pavement of the runway is chosen, the next step is to perform laboratory tests in order to determine the bending tensile stress at 28 days $\mathrm{R}_{\mathrm{ti2} 2}$. This stress is amplified by the increase coefficient in time up to 90 days $\mathrm{R}_{\mathrm{ti} 90}=1.1 \mathrm{x} \mathrm{R}_{\mathrm{ti2} 8}$.

If we choose a cement concrete reinforced with dispersed steel fibre we can obtain bending tensile stress at 28 days $\mathrm{R}_{\mathrm{ti} 28}=5.0 \mathrm{MPa}$ and an elasticity modulus of $40000 \mathrm{MPa}$ resulting $\mathrm{R}_{\mathrm{ti} 90}=$ $5,5 \mathrm{MPa}$. We adopt safety coefficient $\mathrm{c}_{\mathrm{s}}=1,8$ for construction and expansion joint with dowel, resulting $\sigma_{\mathrm{tadm}}=\mathrm{R}_{\mathrm{ti} 0} / 1.8=3.05 \mathrm{MPa}$. Based on in situ testing the reaction modulus at foundation layer is $\mathrm{k}_{0}=70 \mathrm{MN} / \mathrm{m}^{3}$. Depending on the layers of the airport pavement structure we calculate $\mathrm{H}_{\mathrm{eq}}$.

The characteristics of the materials in the composition of the foundation layers: levelling layer compose of sand with a thickness of $15 \mathrm{~cm}$; capillarity-preventing layer composed of ballast with thickness of $30 \mathrm{~cm}$; foundation layer composed of cement stabilised ballast with a thickness of 20 $\mathrm{cm}$.

Table 6. The values of equivalence coefficient of layer

\begin{tabular}{|l|l|}
\hline Ballast stabilised by pozzolana binders & 1.50 \\
\hline Crushed stone & 1.00 \\
\hline Sand stabilised by pozzolana binders & 1.00 \\
\hline Ballast & 0.75 \\
\hline Sand & 0.50 \\
\hline
\end{tabular}

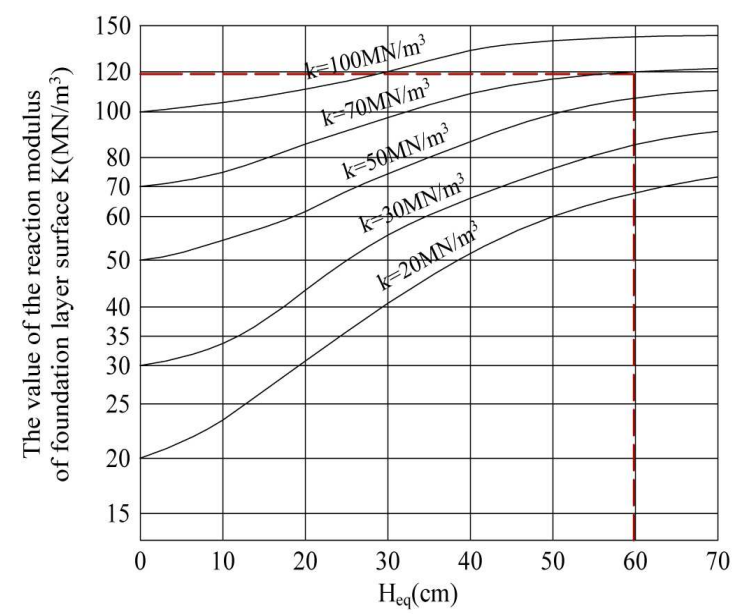

Fig. 13. Reaction modulus at the surface of the foundation layers

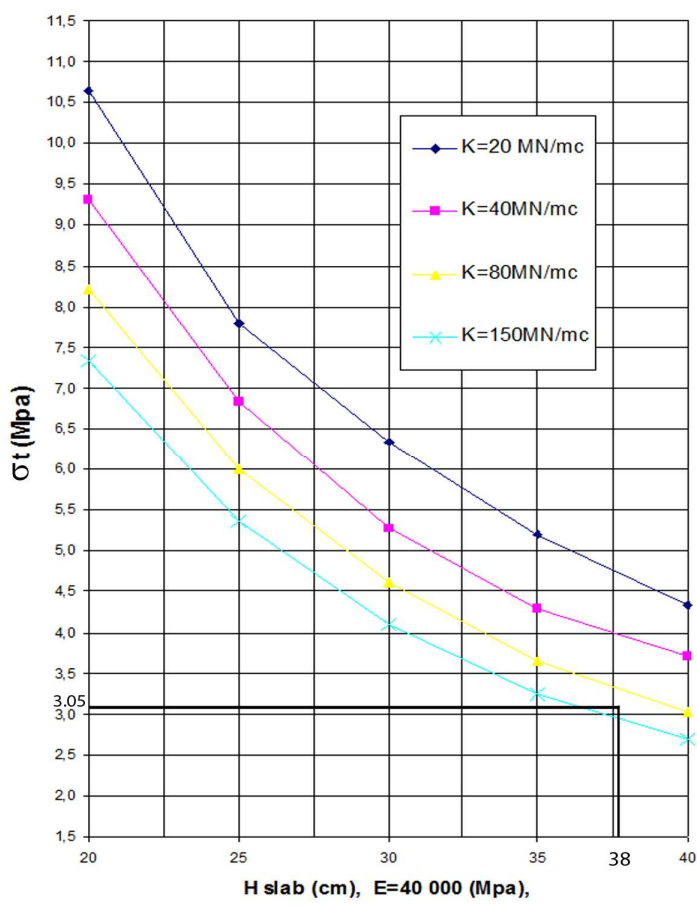

Fig. 14. Design diagram for $E=40000 M P a$, $v_{1}=0.15, P=145 t$, 6 wheel bogie 
The equivalent thickness of the structures below the concrete slab equals the sum of equivalent thickness obtained by multiplying the actual thickness of the layers with equivalence coefficient $\mathrm{c}_{\mathrm{E}}$ (Table 6). $\mathrm{H}_{\mathrm{eq}}=20 \times 1.5+30 \times 0.75+15 \times 0.5=60 \mathrm{~cm}$.

The reaction modulus at the surface of foundation layers $\mathbf{k}$ is determined using diagram from fig. $13[1,10]$ depending on the equivalent thickness of the layers $H_{\text {eq }}$ and on the reaction modulus of the foundation layer $(\mathrm{k})$.

Aircraft Airbus A380 with takeoff mass of $512 \mathrm{tf}$ releases a loading of $145 \mathrm{kN}$ on the main landing gear (body gear). Considering all parameters value for design methodology: $\mathrm{P}=145 \mathrm{kN}$, $\mathrm{k}=120 \mathrm{MN} / \mathrm{m}^{3}, \sigma_{\mathrm{tadm}}=3.05 \mathrm{MPa}, \mathrm{E}=40000 \mathrm{MPa}, v_{1}=0.15$, and the diagram specific to these parameters (Fig. 14), the thickness of the concrete slab is obtained: $\mathrm{H}_{\mathrm{slab}}=38 \mathrm{~cm}$.

To determine the thicknesses exact value of the concrete slab and to exclude the human error from the graphic interpretation the Weibull interpolation correlation function, presented above (Table 5), can be used.

\section{Conclusions}

1. Using concretes with different characteristics is necessary to make the design calculation with exact values of the parameters. Using just a single average value of the concrete parameters leads to large differences of the resulted $\sigma_{t}$ tensile stress.

2. The diagrams developed in this research allow the design of airport rigid pavement structure for six footprint tire loading gear external loads (from this category takes part Airbus A380 and Boeing 777).

3. These design diagrams are applicable for the use of a large spectrum of concrete types.

4. It will be developed a software to reduce the design time and to increase the results accurateness, as well as a practical guide to design airport rigid pavement structure.

ACKNOWLEDGMENT: This paper was supported by the project "Develop and support multidisciplinary postdoctoral programs in primordial technical areas of national strategy of the research - development - innovation" 4D-POSTDOC, contract nr. POSDRU/89/1.5/S/52603, project co-funded from European Social Fund through Sectorial Operational Program Human Resources 2007-2013.

\section{References}

[1] Abdo J., "Chaussees aeronautiques en beton hydraulique. Guide tehnique pour la construction des chaussees aeronautiques neuves en beton hydrauliques " LCPC, STBA, 2000

[2] G. Griffiths, N. Thom, "Concrete Pavement Design Guidance Notes" New York 2007

[3] Navneet G., - Concrete Airfield Pavement Design - Using FAARFIELD for Rigid Overlays, Concrete Airport Pavement Workshop Atlanta, Georgia, 2009

[4] Zarojanu H. Gh., Bulgaru G. D., "Aeroporturi", Iasi, 2010

[5] Zarojanu H. Gh., Ciongradi I., Budescu M., Rosca O., "Finite element Modeling of the reinforced Airport Slabs" Vol. Proceedings of the 5th International Conference on Boundary and Finite Element, Oradea, 2000.

[6] Andrei R., Taranu N.,Cojocaru R., - Numerical analysis and parametric study of SFRC pavements subjected to traffic, EcoLanes FP6 Project, 2009.

[7] Andrei R., Taranu N.,Cojocaru R., - Algorithms and software for the design of SFRC pavements, EcoLanes FP6 Project, 2009.

[8] R. Cojocaru, - The Dessign of the Airport Rigid Pavement Structure, Tomul LVII, Fasc2, Buletinul Institutului politehnic din Iasi, Iasi (2011)

[9] R. Cojocaru, J. C. Pais, R. Andrei , M. Budescu, - Modelling of Airport Rigid Pavement Structure Made of RCC and Recycled Cement Concrete for Complex Configuration of Landing Gears, enviBUILD- International Conference Buildings and Enveroment, Brno, (2012)

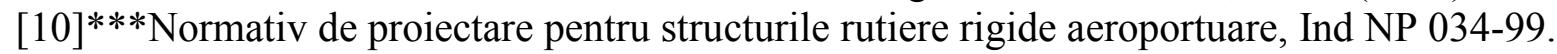

$[11]^{* * *}$ Normativ de proiectare a ranforsarii cu beton de ciment a structurilor rutiere rigide aeroportiare Ind NP 038-99. 